\title{
Comparative whole corona fingerprinting and protein adsorption thermodynamics of PLGA and PCL nanoparticles in human serum
}

\author{
Myolisi Ndumiso $^{a, 1}$, Nela Buchtová ${ }^{b, 1}$, Lizex Husselmann ${ }^{c}$, Gadija Mohamed ${ }^{c}$, Ashwil Klein ${ }^{c}$, \\ Marique Aucamp $^{\mathrm{a}}$, David Canevet ${ }^{\mathrm{d}}$, Sarah D'Souza ${ }^{\mathrm{a}}$, Retsepile E. Maphasa ${ }^{\mathrm{a}}$, Frank Boury ${ }^{\mathrm{b}}$, \\ Admire Dube ${ }^{\mathrm{a}, *}$
}

${ }^{a}$ School of Pharmacy, University of the Western Cape, Cape Town, South Africa

${ }^{\mathrm{b}}$ CRCINA, INSERM, Université de Nantes, Université d'Angers, Angers, France

${ }^{\mathrm{c}}$ Department of Biotechnology, University of the Western Cape, Cape Town, South Africa

${ }^{\mathrm{d}}$ Université d'Angers, Laboratoire MOLTECH-Anjou, UMR CNRS 6200, Angers, France

\section{A R T I C L E I N F O}

\section{Keywords:}

PLGA and PCL nanoparticles

Nanoparticle protein corona

Human serum and nanoparticles

Protein adsorption

Thermodynamics of protein binding

\begin{abstract}
A B S T R A C T
Nanoparticles (NPs) based on biocompatible and biodegradable polymers such as poly(lactic-co-glycolic acid) (PLGA) and polycaprolactone (PCL) represent effective systems for systemic drug delivery. Upon injection into the blood circuit, the NP surface is rapidly modified due to adsorption of proteins that form a 'protein corona' (PC). The PC plays an important role in cellular targeting, uptake and NP bio-distribution. Hence, the study of interactions between NPs and serum proteins appears as key for biomedical applications and safety of NPs. In the present work, we report on the comparative protein fluorescence quenching extent, thermodynamics of protein binding and identification of proteins in the soft and hard corona layers of PLGA and PCL NPs. NPs were prepared via a single emulsion-solvent evaporation technique and characterized with respect to size, zeta potential, surface morphology and hydrophobicity. Protein fluorescence quenching experiments were performed against human serum albumin. The thermodynamics of serum protein binding onto the NPs was studied using isothermal titration calorimetry. Semi-quantitative analysis of proteins in the PC layers was conducted using gel electrophoresis and mass spectrometry using human serum. Our results demonstrated the influence of particle hydrophobicity on the thermodynamics of protein binding. Human serum proteins bind to a greater extent and with greater affinity to PCL NPs than PLGA NPs. Several proteins were detected in the hard and soft corona of the NPs, representing their unique proteome fingerprints. Some proteins were unique to the PCL NPs. We anticipate that our findings will assist with rational design of polymeric NPs for effective drug delivery applications.
\end{abstract}

\section{Introduction}

Polymeric biodegradable nanoparticles (NPs) are among the most explored systems for drug delivery. Indeed, there are a number of FDA approved nanomedicines which are based on polymeric biodegradable NPs [1]. Amongst the most widely used polymers in the synthesis of biodegradable NPs are the polyesters poly(lactic-co-glycolic acid) (PLGA) and polycaprolactone (PCL) [2-5]. PLGA is composed of the monomers lactic and glycolic acid which impart a hydrophobic character to the polymer. Typically, oil in water $(\mathrm{O} / \mathrm{W})$ nano-emulsions prepared from the polymer are useful for achieving encapsulation of hydrophobic drug cargo and sustained drug release [6]. The more hydrophobic polymer PCL is formed by the polymerization of $\varepsilon$ - caprolactone, and nano-emulsions from this polymer also serve the same purpose as those of PLGA [5].

NPs are able to alter the pharmacokinetics (PK) of drugs [7]; a result of reversible partitioning of NPs between blood, tissue and cellular compartments whilst releasing drug cargo within these compartments. While one can engineer and characterize a NP in vitro, when introduced to blood, the NP attains a new identity (i.e. a bio-identity) primarily due to adsorption of proteins (as well as lipids) which coat the NP's surface forming what is known as a 'protein corona' (PC) [8]. Lipids are transported in blood by lipoproteins, and the corona around NPs has been reported to be enriched by lipoproteins [9]. It is the bio-identity of the NP that ultimately dictates the NP's PK, as well as its targeting, uptake and bio-distribution profile within the body [10-12]. The PC is a

\footnotetext{
* Corresponding author.

E-mail address: adube@uwc.ac.za (A. Dube).

${ }^{1}$ Joint first authors.
} 
fingerprint, unique for each NP type and influenced largely by NP size, shape and surface chemistry [11-13]. Adsorbed layers of proteins, with one layer strongly bound to the NP's surface and other layer(s), weakly bound and in dynamic exchange with the environment have been described $[8,9,14,15]$. Therefore, knowledge of the composition and spatial organization of the PC covering the NP carrier is essential. This consideration provides the context for determining structure-activity relationships of nanomedicines and also supports a rational approach to NP design. In other words, characterization of the PC formed on NPs could assist to 'back engineer' NPs, which will attain a desired PC in vivo and resultant $\mathrm{PK}$ and pharmacodynamic profile, i.e. a quality by design approach. Such an approach could accelerate the development and translation of nanomedicines $[16,17]$.

In recent times, there have been studies to characterize the PC formed on NPs [12,14,18-22]. However, much focus has been placed on polystyrene and metallic NPs (e.g. gold and silver NPs [22-24]). While other studies have reported the PC on PLGA NPs [20,21], the present study sought to compare the PC composition between poly (vinyl alcohol) (PVA) stabilized PLGA and PCL NPs in human serum, and to determine the thermodynamics of protein binding. We have applied techniques such as gel electrophoresis coupled with liquid chromatography mass spectrometry analysis (LC-MS/MS), fluorescence quenching and isothermal titration calorimetry (ITC) to characterize the PC and determine protein binding thermodynamics, respectively. We worked with 'native' PLGA and PCL NPs, i.e. in the absence of any surface modifications, in order to characterize the intrinsic behaviour of these NPs in the biological fluids. The average size and size distribution of the PLGA and PCL NPs synthesized in this study is similar to that reported in many studies in literature, making the findings of this study generally applicable.

\section{Materials and methods}

\subsection{Materials}

The following products were purchased from Sigma Aldrich: PVA, $\left(\mathrm{M}_{\mathrm{w}}\right.$ 13.000-23.000), PLGA (ratio of lactic acid:glycolic acid 50:50; $\mathrm{M}_{\mathrm{w}}$ 30 000-60 000), PCL (average $M_{w} 14000$, average $M_{n} 10.000$ by gel permeation chromatography), human serum albumin ((HSA), $\geq 99 \%$ lyophilized powder, fatty acid and globulin free), human serum (from human male $A B$ plasma, USA origin, sterile-filtered), rose Bengal (RB), lithium dodecyl sulphate (LDS), dithiothreitol (DTT), sucrose ( $\geq 99.5$ $\%$ ), sodium hydroxide $(\mathrm{NaOH})$, monopotassium phosphate $\left(\mathrm{KH}_{2} \mathrm{PO}_{4}\right)$, dipotassium phosphate $\left(\mathrm{K}_{2} \mathrm{HPO}_{4}\right)$, ammonium bicarbonate $\left(\mathrm{NH}_{4} \mathrm{HCO}_{3}\right)$, formic acid (FA), trifluoroacetic acid (TFA), acetonitrile (ACN), triscarboxyethyl phosphine (TCEP) and iodoacetamide (IAA). Dichloromethane (DCM) and hydrochloric acid ( $\mathrm{HCl}$ ) were supplied by Kimix Chemicals, South Africa. Sequencing grade modified trypsin was purchased from Promega (USA). Milli-Q water was obtained from Thermo Scientific Barnstead ${ }^{\mathrm{TM}}$ Smart2Pure ${ }^{\mathrm{TM}}$ Water Purification System.

\subsection{Synthesis of NPS}

The method of NPs synthesis was adapted from our prior work [25]. Briefly, $0.5 \%(\mathrm{w} / \mathrm{v})$ of PVA was dissolved in Milli-Q water at $120^{\circ} \mathrm{C}$ within $1 \mathrm{~h}$ under vigorous magnetic stirring. The solution was cooled down and filtered through $0.22 \mu \mathrm{m}$ filter. Simultaneously, $1 \%$ (w/v) of PLGA or PCL polymer was dissolved in DCM at room temperature. Thereafter, 10 volumes of PVA aqueous solution were mixed with $1 \mathrm{vol}$ of PLGA or PCL solution under probe sonication (Bandelin SONOPULS, HD2070, $55 \%$ amplitude) for $3 \mathrm{~min}$ in an ice bath. The PLGA or PCL solution was added dropwise within the first minute of sonication. Evaporation of DCM was performed using a rotavapor (Büchi Rotavapor R2, Germany) for $15 \mathrm{~min}$. PLGA or PCL NPs were collected after a single wash with Milli-Q water and $15 \mathrm{~min}$ of centrifugation at $10000 \mathrm{x} \mathrm{g}$. Finally, NPs were re-dispersed in Milli-Q water and sucrose (as cryoprotectant) was added to the NPs suspension prior freeze-drying $(10: 1 \mathrm{w} / \mathrm{w})$. After freeze-drying NPs were stored in a desiccator prior to characterization.

\subsection{Characterization of NPs size, zeta potential and shape}

Particle size ( $z$-average hydrodynamic diameter, $\mathrm{H}_{\mathrm{d}}$ ) and zeta potential of NPs were determined using a Zetasizer Nano ZS90 (Malvern Instruments Ltd.). NPs size and polydispersity index (PDI) were determined using dynamic light scattering after freeze-drying following by re-dispersion of NPs in Milli-Q water for $5 \mathrm{~min}$ in ultrasonic bath. The average values were obtained from 3 different samples; 3 measurements with 10 scans per measurement were performed for each sample at $25^{\circ} \mathrm{C}$. The errors were calculated as standard deviations (s.d.) of each average value. For zeta potential measurements, freeze-dried NPs were also re-dispersed in Milli-Q water for $5 \mathrm{~min}$ in ultrasonic bath. Zeta potential values were determined using laser Doppler microelectrophoresis averaging 3 measurements with 10 scans per measurement for 3 different samples. Scanning electron microscopy (SEM) was performed on Zeiss AURIGA ${ }^{\oplus}$ SEM working at $5 \mathrm{kV}$ voltage and using NPs freeze-dried without cryoprotectant (sucrose). A small quantity of NPs was spread on carbon double-side tape stuck on SEM stub. Samples were sputter-coated with gold-palladium prior to any observation.

\subsection{Characterization of surface hydrophobicity of the NPs}

The hydrophobicity of the PLGA and PCL NPs was measured using the surface adsorption method described by Xiao and Wiesner [26]. The relative adsorption of Rose Bengal (RB) onto the NPs was evaluated. $12.5 \mu \mathrm{g} / \mathrm{ml}$ of $\mathrm{RB}$ was added to PLGA and PCL NPs separately (NP concentrations ranged from $0.1-2 \mathrm{mg} / \mathrm{ml}$ in $\mathrm{PBS} \mathrm{pH}$ 7.4). Controls of $\mathrm{RB}$ in PBS to account for any adsorption of RB to tubes were prepared. Samples were incubated for $3 \mathrm{~h}$ at room temperature. Thereafter, NPs were settled by centrifugation at $15000 \mathrm{x} \mathrm{g}$ at $4{ }^{\circ} \mathrm{C}$ for $20 \mathrm{~min}$. The absorbance of free RB in the supernatant was determined by UV-vis absorption spectroscopy at $542 \mathrm{~nm}$. A linear relationship between absorbance and RB concentration in PBS was pre-established over the range $6.25-50 \mu \mathrm{g} / \mathrm{ml}\left(\mathrm{r}^{2}=0.9991\right)$. The percentage of adsorption of $\mathrm{RB}$ onto the NPs was calculated using the following equation (Eq. (1)):

$$
\begin{aligned}
& \% \text { adsorption of } \mathrm{RB}=\frac{\text { Concentration of } \mathrm{RB} \text { in control }- \text { Concentration of } \mathrm{RB} \text { in sample supernatant }}{\text { Concentration of } \mathrm{RB} \text { in control }} \\
& \times 100
\end{aligned}
$$

\subsection{Determination of extent of protein fluorescence quenching}

Steady-state fluorescence quenching measurements were performed against HSA $(1.32 \mu \mathrm{M})$ in the presence of an increasing concentration of either PLGA or PCL NPs $(0.1-2 \mathrm{mg} / \mathrm{ml})$. The HSA-NPs suspensions (in $\mathrm{PBS} \mathrm{pH}$ 7.5) were incubated in a 96 well plate (low protein binding) for $1 \mathrm{~h}$ at $37^{\circ} \mathrm{C}$ with gentle shaking. Samples were analyzed in a fluorescence microplate reader (Synergy Mx, BioTek Instruments, USA) and fluorescence spectra were obtained after $5 \mathrm{~min}$ in the range of $320-400 \mathrm{~nm}$ after excitation at $280 \mathrm{~nm}$. HSA contains one tryptophan residue, which makes it adsorb and fluoresce light at these wavelengths. HSA, PLGA and PCL NPs alone in PBS were also included as controls. The HSA is expected to bind to the NPs resulting in a quenching of fluorescence. The area under each fluorescence curve (AUC) was integrated and used to calculate the percentage of protein fluorescence quenching using the following equation (Eq. (2)):

$\%$ Quenching $=\frac{(\text { Fluorescence }(\text { AUC }) \text { of HSA }- \text { fluorescence }(\text { AUC }) \text { of HSA }+ \text { NPs })}{\text { Fluorescence }(\text { AUC }) \text { of HSA }}$ $\times 100$ 


\subsection{Determination of thermodynamics of protein binding to the NPs using} isothermal titration calorimetry

ITC experiments were carried out on Nano ITC calorimeter (TA Instruments, USA) at $37{ }^{\circ} \mathrm{C}$. A dispersion of PLGA or PCL NPs in PBS pH $7.4(2.2 \mathrm{mg} / \mathrm{ml})$ was poured into the sample cell and HSA $(40 \mathrm{mg} / \mathrm{ml}$ in PBS pH 7.4) or human serum solution (1:1 vol dilution in PBS pH 7.4) was progressively titrated $(25 \times 10 \mu \mathrm{l})$. The time between the titration steps was fixed to $700 \mathrm{~s}$ such that the system reached an equilibrium state. The NP dispersion in the sample cell was constantly stirred at $250 \mathrm{rpm}$ during the experiment. In order to determine the heat of dilution, pure PBS was titrated to PBS containing either NP dispersion (i.e. NPs and sucrose), or sucrose. For these blank experiments, the concentrations were the same as those mentioned above. Analysis of ITC curves was performed using the NanoAnalyze ${ }^{\mathrm{TM}}$ software (TA Instruments, USA) using an independent model. The thermodynamic parameters that characterize the protein binding were obtained using the following equations (Eqs. (3) and (4)):

$\Delta \mathrm{G}=\Delta \mathrm{H}-\mathrm{T} \Delta \mathrm{S}$

$\Delta \mathrm{G}=-\mathrm{RT} \ln \mathrm{K}_{\mathrm{B}}$

where $\Delta \mathrm{G}$ is the change in Gibbs free energy of binding, $\Delta \mathrm{H}$ and $\Delta \mathrm{S}$ are the enthalpy and entropy changes, respectively, and $\mathrm{K}_{\mathrm{B}}$ represents the binding constant. The gas constant $\mathrm{R}=8.314 \mathrm{~J} / \mathrm{K} . \mathrm{mol}$.

\subsection{Collection and characterization of the NP's protein corona}

The method employed to collect the corona was adapted from Walkey et al. [23]. A PLGA or PCL NPs suspension $(0.4 \mu \mathrm{g} / \mathrm{ml})$ prepared in PBS pH 7.5 was added to a human serum (HS) solution at a 1:1 vol ratio ( $1 \mathrm{ml}$ total). The stock HS was diluted 1:50 in $2 \mathrm{X}$ PBS buffer at $\mathrm{pH}$ 7.5. The preparations were mixed in low-protein binding centrifuge tubes (Eppendorf LoBind ${ }^{\mathrm{TM}}$ tubes). The negative control consisted of the same preparation without NPs and the positive control consisted only of diluted serum. The preparations were incubated for $90 \mathrm{~min}$ at $37^{\circ} \mathrm{C}$ in a shaking water bath and thereafter the samples were centrifuged at 15 $000 \mathrm{x} \mathrm{g}$ at $4{ }^{\circ} \mathrm{C}$ for $15 \mathrm{~min}$. The supernatant containing unbound proteins was collected as 'wash 1 '. $1 \mathrm{ml}$ of $10 \mathrm{mM}$ PBS buffer at $\mathrm{pH} 7.5$ supplemented with $0.05 \%$ (w/v) Tween 20 was added to the pellet. The pellet was reconstituted by bath sonication for $5 \mathrm{~min}$ and thereafter centrifuged at $15000 \mathrm{x} \mathrm{g}$ at $4{ }^{\circ} \mathrm{C}$ for $15 \mathrm{~min}$. The supernatant containing the weakly bound corona was collected as 'wash 2'. PBS buffer $(988 \mu \mathrm{l})$ at $\mathrm{pH} 7.5,8 \mu \mathrm{l}$ of $4 \mathrm{X}$ lithium dodecyl sulphate and $4 \mu \mathrm{l}$ of $500 \mathrm{nM}$ DLdithiothreitol (DTT) were added to the pellet. The latter was reconstituted by vortexing, and thereafter incubated at $70^{\circ} \mathrm{C}$ for $1 \mathrm{~h}$ in a shaking water bath. The samples were then centrifuged at $15000 \mathrm{x} \mathrm{g}$ at $4{ }^{\circ} \mathrm{C}$ for $15 \mathrm{~min}$, and the supernatant containing the strongly bound corona was collected as 'wash 3'. All protein and corona samples collected were stored at $-80^{\circ} \mathrm{C}$ until analysis. Fig. S1 in Supplementary data is a schematic of the corona collection protocol.

\subsection{Sodium dodecyl sulphate polyacrylamide gel electrophoresis (SDS- PAGE) analysis of the corona}

A fraction of each wash ( $3 \mu \mathrm{g}$ of each protein sample) was denatured and size fractionated on a $12 \%$ SDS-PAGE gel for $90 \mathrm{~min}$ at $120 \mathrm{~V}$. After gel electrophoresis, the SDS-PAGE gel was stained with Coomassie Brilliant Blue G-250 for $30 \mathrm{~min}$ and transferred to a de-staining solution (10\% glacial acetic acid and $1 \%$ glycerol) for $2 \mathrm{~h}$. The resolved protein bands were visualized using the ENDURO ${ }^{\mathrm{TM}}$ GDS Gel Documentation System (Labnet International, Edison, NJ). Gel processing and in-gel digestion were performed as described by Piersma et al. [27] with slight modifications. The SDS-PAGE gel was divided into different zones prior to in-gel tryptic digestion. Gel bands were excised from the Coomassiestained SDS-PAGE gel and transferred to $2 \mathrm{ml}$ LoBind ${ }^{\mathrm{TM}}$ Eppendorf tubes
(Hamburg, Germany) for further processing. Gel bands were washed/ de-stained in $200 \mu \mathrm{l}$ of $25 \mathrm{mM} \mathrm{NH}_{4} \mathrm{HCO}_{3} / 50 \% \mathrm{ACN}$ for $45 \mathrm{~min}$. The gel bands were dehydrated in $100 \mu \mathrm{l}$ of ACN and reduced in $2 \mathrm{mM}$ TCEP in $25 \mathrm{mM} \mathrm{NH}_{4} \mathrm{HCO}_{3}$ for $15 \mathrm{~min}$ at room temperature with moderate agitation. Excess TCEP was removed and cysteine residues carbamidomethylated with $20 \mathrm{mM}$ iodoacetamide in $25 \mathrm{mM} \mathrm{NH}_{4} \mathrm{HCO}_{3}$ for $30 \mathrm{~min}$ in the dark at room temperature. The gel bands were washed with $25 \mathrm{mM} \mathrm{NH}_{4} \mathrm{HCO}_{3}$ followed by another dehydration step. Proteins were digested by rehydrating the gel cubes in a trypsin solution $(10-20 \mathrm{ng} /$ $\mu \mathrm{l})$ in $25 \mathrm{mM} \mathrm{NH} \mathrm{NCO}_{3}$ and incubating at $37{ }^{\circ} \mathrm{C}$ overnight. Peptides were extracted from gel cubes with $30 \%$ ACN/0.1 \% TFA for $45 \mathrm{~min}$ at room temperature with intermittent vortexing. The samples were dried down to remove residual $\mathrm{NH}_{4} \mathrm{HCO}_{3}$, re-dissolved in $0.1 \%$ TFA and further purified and concentrated using $\mathrm{C}_{18}$ ZipTip $^{\circledR}$ according to manufacturer's instructions. The purified peptides were dried in a SpeedVac $^{\circledR}$ followed by resuspension in $10 \mu$ l of $0.1 \%$ TFA. Samples were stored at $-20^{\circ} \mathrm{C}$ prior to nano-flow reversed-phase LC-MS/MS analysis.

\subsection{Peptide fractionation and detection using $L C-M S / M S$}

A high-pressure liquid chromatography system running at nanoflow rates was used for peptide fractionation prior to mass spectrometry analysis. The method for LC-MS/MS analysis was adapted from [28]. Chromatography was performed using a Thermo Scientific Ultimate 3000 RSLC equipped with a $2 \mathrm{~cm} \times 100 \mu \mathrm{m} \mathrm{C} 18$ trap column and a $35 \mathrm{~cm}$ $\mathrm{x} 75 \mu \mathrm{m} \mathrm{C}_{18}$ analytical column (Luna $\mathrm{C}_{18}, 5 \mu \mathrm{m}$; Phenomenex). The solvent system employed was loading: $2 \%$ ACN : water; $0.1 \%$ FA; Solvent A: 2 \% ACN : water; $0.1 \%$ FA and Solvent B: $100 \%$ ACN : water. Samples were loaded onto the trap column using loading solvent at a flow rate of $15 \mu \mathrm{l} / \mathrm{min}$ from a temperature controlled autosampler set at $7{ }^{\circ} \mathrm{C}$. The flow rate was set to $500 \mathrm{nl} / \mathrm{min}$ and a gradient generated as follows: $2-10 \%$ solvent B over $5 \mathrm{~min} ; 5 \%-25 \%$ solvent B from 5 to 50 min using Chromeleon non-linear gradient 6, $25 \%-45 \%$ from 50 to $65 \mathrm{~min}$. Chromatography was performed at $50^{\circ} \mathrm{C}$ and the outflow delivered to the mass spectrometer through a stainless steel nano-bore emitter. Detection was performed using a Thermo Scientific Fusion mass spectrometer equipped with a Nanospray Flex ionization source. The sample was introduced through a stainless-steel emitter. Data were collected in a positive mode with spray voltage set to $2 \mathrm{kV}$ and ion transfer capillary set to $275^{\circ} \mathrm{C}$. Spectra were internally calibrated using polysiloxane ions at $m / z=445.12003$ and 371.10024. MS1 scans were performed using the orbitrap detector set at 120000 resolution over the scan range 350-1650 with AGC target at 3 E5 and maximum injection time of $40 \mathrm{~ms}$. Data were acquired in profile mode. MS2 acquisitions were performed using monoisotopic precursor selection for ion with charges $+2-+6$ with error tolerance set to $+/-0.02 \mathrm{ppm}$. Precursor ions were excluded from fragmentation once for a period of $30 \mathrm{~s}$. Precursor ions were selected for fragmentation in higher energy dissociation (HCD) mode using the quadrupole mass analyzer with HCD energy set to $32.5 \%$. Fragment ions were detected in the orbitrap mass analyzer set to 15000 resolution. The AGC target was set to $1 \mathrm{E} 4$ and the maximum injection time to $45 \mathrm{~ms}$. The data were acquired in centroid mode.

\subsection{Protein validation and data analysis}

The raw files generated by the MS were imported into Proteome Discoverer v1.4 software (Thermo Scientific, USA) and processed using Sequest algorithm. Database interrogation was performed against a concatenated database created using the Uniprot human database with semi-tryptic cleavage allowing for 2 missed cleavages. Precursor mass tolerance was set to $10 \mathrm{ppm}$ and fragment mass tolerance set to $0.02 \mathrm{Da}$. Deamidation (NQ) and oxidation (M) was allowed as dynamic modifications and carbamidomethylation of $\mathrm{C}$ as static modification. Peptide validation was performed using the peptide validator node set 
to search against a decoy database with strict false discovery rate (FDR) of $1 \%$ and delta $\mathrm{Cn}$ of 0.1 (delta $\mathrm{Cn}$ being the measure of specificity of fit of the experimental data against that in the database). The result files were imported into Scaffold 4.8.8 and identified peptides validated using the X!Tandem search algorithm included in Scaffold. Peptide and protein validation were done using the Peptide and Protein Prophet algorithms. Protein quantitation was performed using Fischer's Exact Test on the paired data with the Benjamini-Hochberg correction applied. Protein identifications were accepted if they could be established at greater than $95 \%$ probability and contained at least two unique identified peptides.

\subsection{Statistical analysis}

All the data are presented as mean \pm s.d. $(n \geq 3)$, unless otherwise noted. The statistical analysis of the data was carried out using the Student's $t$-test or two-way ANOVA using GraphPad Prism 8.10 software (GraphPad, CA). Statistical differences were considered at $\mathrm{p}<0.05$.

\section{Results and discussion}

\subsection{NPs synthesis and characterization}

A number of techniques exist to prepare PLGA and PCL NPs such as emulsification, nanoprecipitation or spray-drying. The most commonly applied method is based on single emulsion-solvent evaporation [29], and this method was used to synthesize the NPs in this study.

Both polymers produced particle populations with a polydispersity index (PDI) of approximately 0.2 (see Fig. 1A). PCL-based NPs had a larger $H_{d}$ than PLGA NPs $(559 \pm 53 \mathrm{~nm} v s .416 \pm 41 \mathrm{~nm}, \mathrm{p}=0.021)$ even though synthesis conditions were the same. This could be due to the difference in hydrophobicity between the two polymers. In $\mathrm{O} / \mathrm{W}$ emulsions, the phenomenon of Ostwald ripening often occurs, i.e. molecules from small oil droplets can diffuse through the aqueous phase to join larger oil droplets in order to reach a more thermodynamically stable state [30]. As PCL polymer is more hydrophobic than PLGA polymer [31], the oil droplets with dissolved PCL and consequently the diameter of precipitated PCL NPs will be slightly larger than that of PLGA NPs, even though the emulsion stabilizer (PVA) is present during the emulsification. It should be noted that although there was a significant difference in the z-average $\mathrm{H}_{\mathrm{d}}$ between the particle types, significant overlap in the particle populations (particle size distribution) was observed, and hence it is not expected that particle size will play a significant role in influencing protein binding between the two NP types. Under microscopy, both PLGA and PCL NPs were observed to be spherical in shape and their surface appeared smooth (Fig. 1B).

The zeta potential was determined on freeze-dried NPs re-dispersed in water. The zeta potential of both types of NPs were negative and of approximately the same value, i.e. $-18 \pm 2 \mathrm{mV}$ and $-18 \pm 3 \mathrm{mV}$ respectively for PLGA and PCL NPs (Fig. 1A). Therefore, aggregation of nanoparticles could not be observed due to sufficient electrostatic repulsions, indicating a good NPs stability in suspension.

\subsection{Hydrophobicity of NPs surface}

The hydrophobicity of the PLGA and PCL NPs was characterized using a dye absorption assay. The PCL NPs were observed to be more hydrophobic than the PLGA NPs (Fig. 2). The differences in RB adsorption were more apparent at the higher NPs concentration. No significant difference was found at low NPs concentrations $(0.1 \mathrm{mg} / \mathrm{ml}$ and $0.5 \mathrm{mg} / \mathrm{ml}$ ) with p-values of 0.1527 and 0.8472 , respectively. However, a significant difference was observed at NPs concentration of $2 \mathrm{mg} / \mathrm{ml}$ $(\mathrm{p}=0.0037)$, and $\%$ adsorption of $\mathrm{RB}$ was $40.5 \pm 2.7 \%$ and $27.7 \pm 5.6 \%$ onto the PCL and PLGA NPs, respectively. RB is negatively charged and some repulsion by the negative surface of the PLGA and PCL NPs would be expected, although this effect is expected to play a relatively minor role (in $\mathrm{RB}$ binding) in relation to the hydrophobicity of the NP surface [26]. However, the relative hydrophobicity of the NPs provides an indication of the expected extent and rate of protein binding, with the more hydrophobic PCL NP anticipated to bind more proteins at a faster rate in comparison to the less hydrophobic NPs [32].

\subsection{Fluorescence quenching}

The PCL and PLGA NPs $(0.1-2 \mathrm{mg} / \mathrm{ml})$ were incubated for $5 \mathrm{~min}$ with HSA and the change in fluorescence maxima of HSA was assessed. A significant blue shift of the HSA emission maxima from 335 to $330 \mathrm{~nm}$ and $325 \mathrm{~nm}$ was observed consequent to the addition of PLGA and PCL NPs, respectively (Fig. 3). This indicates a shift of the HSA fluorophore (Tryptophan 214) to a more nonpolar environment and is a result of the hydrophobic interactions with the NPs [15,33]. The more

A

\begin{tabular}{|l|l|l|l|}
\hline & $\mathrm{H}_{d}(\mathrm{~nm})$ & PDI & Zeta potential $(\mathrm{mV})$ \\
\hline PLGA NPS & $416 \pm 41$ & $0.21 \pm 0.10$ & $-18 \pm 2$ \\
\hline PCL NPS & $559 \pm 53$ & $0.19 \pm 0.06$ & $-18 \pm 3$ \\
\hline
\end{tabular}

B
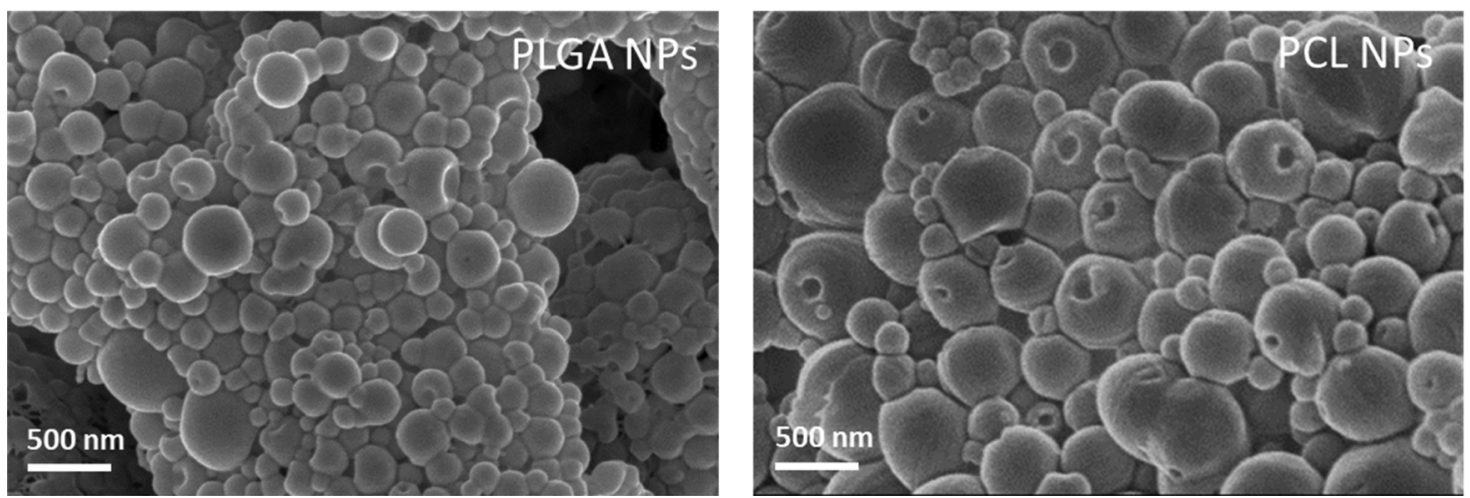

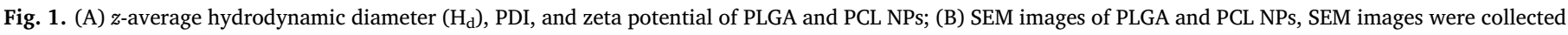
from freeze-dried NPs in the absence of sucrose cryoprotectant. 


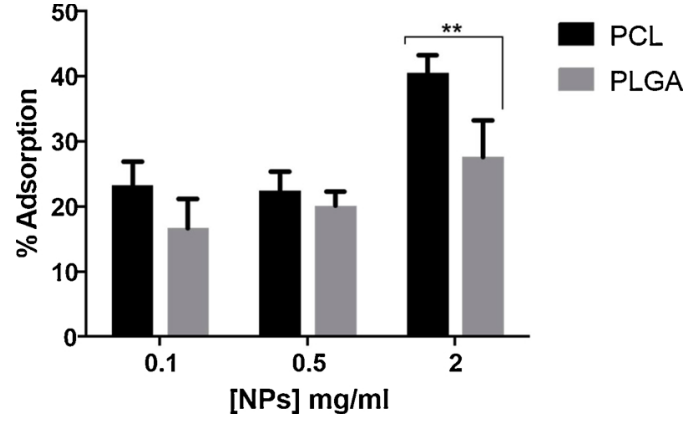

Fig. 2. Percentage (\%) adsorption of Rose Bengal (RB) to PCL and PLGA NPs. Higher \% adsorption onto PCL is observed. A statistically significant difference in adsorption is observed at NPs concentration of $2 \mathrm{mg} / \mathrm{ml}$ (p value $=0.0037$ ).

blue-shifted HSA/PCL NPs emission maxima also confirms the more hydrophobic nature of the PCL NPs compared to the PLGA NPs.

A higher percentage of HSA fluorescence quenching in presence of PCL NPs when compared to PLGA NPs was observed (see column graphs in Fig. 3). However, the statistical analysis shows no significant differences between the percentage quenching with both NPs at concentrations of $0.1,0.5$ and $2 \mathrm{mg} / \mathrm{ml}$.

\subsection{Thermodynamics of protein binding to PLGA and PCL NPS}

ITC is a powerful analytical tool that directly measures the heat released or absorbed during a biomolecular binding event and helps to measure the binding affinity of two biomolecules. When substances bind, heat is either generated or absorbed. Measurement of heat allows accurate determination of binding constants $\left(\mathrm{K}_{\mathrm{B}}\right)$ and enthalpy. The ITC raw heat profiles obtained during these analyses showed that the binding interaction between the PLGA NPs and HSA or serum, as well as between the PCL NPs and HSA or serum was exothermic (data not shown). Using an independent model and Eqs. (3) and (4), we obtained the thermodynamic values resumed in Table 1 .
Table 1

Thermodynamic parameters for the association of HSA and serum to PLGA and PCL NPs.

\begin{tabular}{lllll}
\hline & $\Delta \mathrm{H}(\mathrm{kJ} / \mathrm{mol})$ & $\mathrm{K}_{\mathrm{B}}$ & $-\mathrm{T} \Delta \mathrm{S}(\mathrm{kJ} / \mathrm{mol})$ & $\Delta \mathrm{S}(\mathrm{J} / \mathrm{mol})$ \\
\hline PLGA NPs + HSA & -9.11 & $2.43^{\mathrm{x}} 10^{5}$ & 22.87 & 73.74 \\
PLGA NPs + serum & -4.17 & $3.01^{\mathrm{x}} 10^{3}$ & 16.48 & 53.13 \\
PCL NPs + HSA & -15.96 & $2.43^{\mathrm{x}} 10^{4}$ & 10.09 & 32.52 \\
PCL NPs + serum & -11.58 & $7.52^{\mathrm{x}} 10^{5}$ & 23.31 & 75.16 \\
\hline
\end{tabular}

\subsubsection{Kinetics of binding of HSA and serum to PLGA NPS}

Binding constant values of polymeric NPs-protein interactions generally vary between $10^{5}$ and $10^{7}$ [34-37]. The $\mathrm{K}_{\mathrm{B}}$ value obtained here $\left(2.43^{x} 10^{5}\right)$ is within the lower limit of this range indicating a relatively low binding affinity of HSA to the PLGA NPs. Biomolecular interactions usually involve solvent reorganization (desolvation and solvation) and non-covalent bond formation. When $\Delta \mathrm{H}$ is negative, this is an indication of the exothermic process of non-covalent bond formation which is therefore the case with the interaction of HSA with PLGA NPs. If $\Delta S$ is positive, this is indicative of desolvation occurring during the complexation process. The fact that both $\Delta \mathrm{H}$ and $-\mathrm{T} \Delta \mathrm{S}$ are negative suggests that the binding of the protein to the NPs is governed by non-covalent bonding [38].

For the complexation of human serum with the PLGA NPs, we observed a very small $\mathrm{K}_{\mathrm{B}}$ value $\left(3.01^{\mathrm{x}} 10^{3}\right)$ which indicates that serum has even lower binding affinity to PLGA NPs than HSA. Considering the other thermodynamic parameters, it becomes apparent that the binding of serum proteins with these NPs is also governed by non-covalent bonding. Preliminary results obtained from MicroScale Thermophoresis (Instrument and settings: Monolith ${ }^{\circledR}$ NT.115 ${ }^{\text {Pico }}$, NanoTemper Technologies $\mathrm{GmbH}$ ) gave a dissociation constant of $5.48 \mu \mathrm{M}$ indicating a weak interaction between HSA and PLGA NPs, which is further verifying the data obtained in these ITC experiments

\subsubsection{Kinetics of binding of HSA and serum to PCL NPs}

In comparison with PLGA NPs, HSA shows a lower binding affinity to the PCL NPs $\left(K_{B}=2.43^{x} 10^{4}\right.$, Table 1$)$. The negative $\Delta$ H value implies (a)

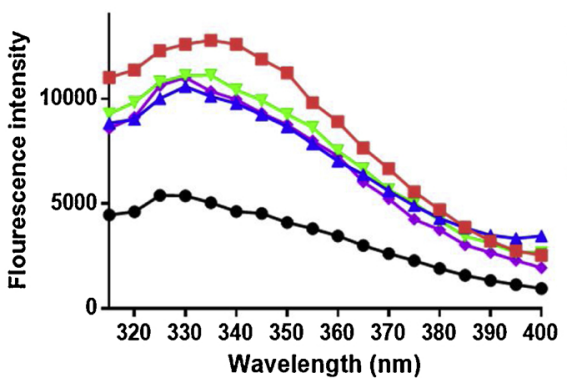

(c)

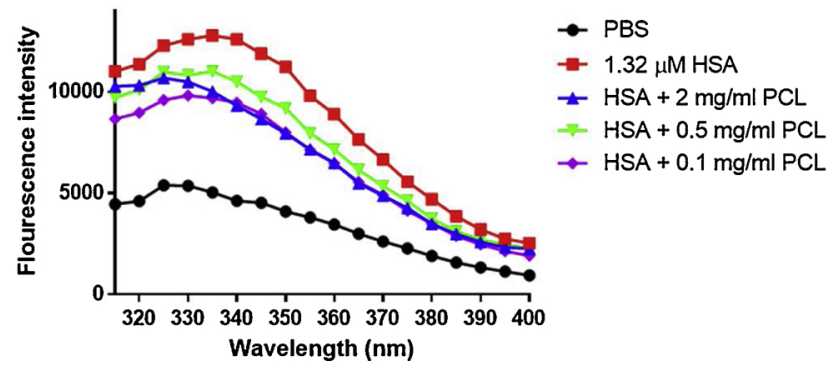

(b)

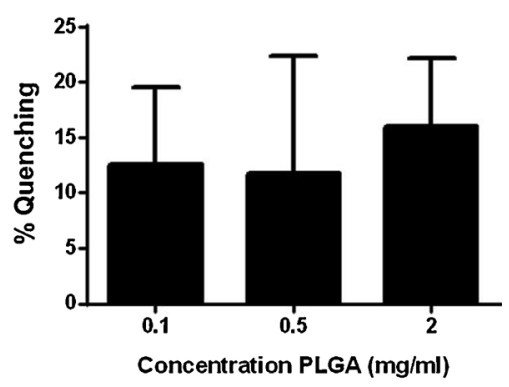

(d)

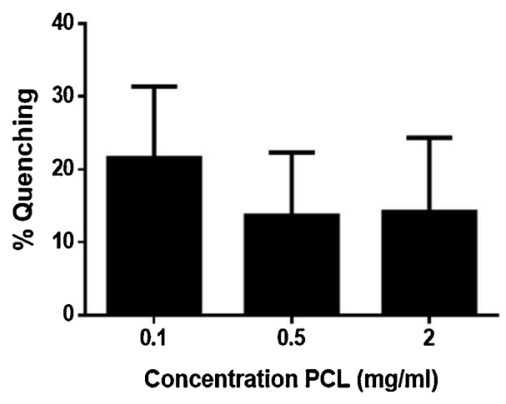

Fig. 3. Fluorescence intensity spectra of HSA alone and in the presence of different concentrations of PLGA (A) and PCL (B) NPs after 5 min of incubation at $37^{\circ} \mathrm{C}$. The fluorescence data were used to calculate the percentage of HSA fluorescence quenching in presence of varying concentrations of PLGA and PCL NPs. Results shown are the mean \pm s.d. 
Table 2

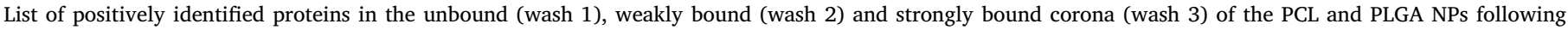
incubation of the NPs with human serum for $90 \mathrm{~min}$. The percentages represent the probability scores of the proteins.

\begin{tabular}{|c|c|c|c|c|c|c|c|c|}
\hline \multirow[t]{2}{*}{ Identified proteins } & \multirow[t]{2}{*}{ Accession numbers } & \multirow[t]{2}{*}{ Molecular Weight (kDa) } & \multicolumn{3}{|c|}{ PCL NPs } & \multicolumn{3}{|c|}{ PLGA NPs } \\
\hline & & & wash 1 & wash 2 & wash 3 & wash 1 & wash 2 & wash 3 \\
\hline Serum albumin & ALBU & 69 & $100 \%$ & $100 \%$ & $100 \%$ & $100 \%$ & $100 \%$ & $100 \%$ \\
\hline Apolipoprotein A-I & P02647|APOA1 & 30 & $100 \%$ & $100 \%$ & $100 \%$ & $100 \%$ & - & - \\
\hline Apolipoprotein B-100 & АРОВ & 516 & $100 \%$ & $100 \%$ & - & - & - & - \\
\hline Serotransferrin & TRFE & 77 & $100 \%$ & $100 \%$ & $100 \%$ & $100 \%$ & - & - \\
\hline Complement C3 & $\mathrm{CO} 3$ & 187 & $100 \%$ & $100 \%$ & $100 \%$ & $100 \%$ & - & - \\
\hline Immunoglobulin gamma-1 heavy chain & P0DOX5|IGG1 & 49 & $100 \%$ & $100 \%$ & $100 \%$ & $100 \%$ & - & - \\
\hline Alpha-2-macroglobulin & A2MG & 163 & $100 \%$ & $100 \%$ & - & $98 \%$ & $100 \%$ & - \\
\hline Haptoglobin & HPT & 45 & $100 \%$ & $100 \%$ & - & $54 \%^{\mathrm{a}}$ & $92 \%^{\mathrm{a}}$ & - \\
\hline Antithrombin-III & ANT3 & 53 & $100 \%$ & $100 \%$ & - & - & - & - \\
\hline Immunoglobulin kappa light chain & P0DOX7|IGK & 23 & $100 \%$ & $100 \%$ & $64 \%{ }^{\mathrm{a}}$ & - & - & - \\
\hline Complement C4-B & $\mathrm{CO} 4 \mathrm{~B}$ & 193 & - & $100 \%$ & - & $72 \%$ a & $100 \%$ & - \\
\hline Inter-alpha-trypsin inhibitor heavy chain $\mathrm{H} 2$ & P19823|ITIH2 & 106 & $100 \%$ & $100 \%$ & - & $96 \%$ & $100 \%$ & - \\
\hline Alpha-1-antitrypsin & A1AT & 47 & $100 \%$ & $100 \%$ & - & - & - & - \\
\hline Immunoglobulin heavy constant alpha 1 & P01876|IGHA1 & 106 & - & $100 \%$ & $60 \%{ }^{\mathrm{a}}$ & $100 \%$ & - & - \\
\hline Alpha-1B-glycoprotein & A1BG & 54 & $100 \%$ & $100 \%$ & - & $100 \%$ & - & - \\
\hline Complement C5 & $\operatorname{co5}$ & 188 & $100 \%$ & $100 \%$ & $40 \%{ }^{\mathrm{a}}$ & - & - & - \\
\hline Ceruloplasmin & CERU & 122 & $100 \%$ & $100 \%$ & - & - & - & - \\
\hline Heparin cofactor 2 & HEP2 & 57 & $100 \%$ & $100 \%$ & - & - & - & - \\
\hline Hemopexin & HEMO & 52 & $100 \%$ & $100 \%$ & - & - & - & - \\
\hline Immunoglobulin heavy variable $3-74$ & HV374 & 13 & - & $100 \%$ & - & - & - & - \\
\hline Cystatin-A & CYTA & 11 & $100 \%$ & $100 \%$ & - & - & - & - \\
\hline Vitronectin & VTNC & 54 & $98 \%$ & $100 \%$ & $100 \%$ & $93 \%{ }^{\mathrm{a}}$ & - & - \\
\hline Inter-alpha-trypsin inhibitor heavy chain $\mathrm{H} 1$ & P19827|ITIH1 & 101 & - & $100 \%$ & - & - & - & - \\
\hline Apolipoprotein E & APOE & 36 & - & $100 \%$ & - & - & - & - \\
\hline Alpha-1-antichymotrypsin & AACT & 48 & $94 \%^{\mathrm{a}}$ & $100 \%$ & $100 \%$ & - & - & - \\
\hline Immunoglobulin kappa variable $3-20$ & P01619|KV320 & 12 & - & $100 \%$ & - & - & $57 \%{ }^{\mathrm{a}}$ & - \\
\hline Immunoglobulin lambda constant 2 & P0DOY2|IGLC2 & 11 & $99 \%$ & $100 \%$ & - & - & - & - \\
\hline Plasma protease $\mathrm{C} 1$ inhibitor & P05155|IC1 & 55 & - & $100 \%$ & - & - & - & - \\
\hline Insulin-like growth factor-binding protein complex acid labile & P35858|ALS & 66 & - & $100 \%$ & - & - & - & - \\
\hline
\end{tabular}

- No proteins detected.

a Proteins with a probability score less than $95 \%$ were not regarded as positive identifications.

that non-covalent bonding occurred between the NPs and the protein with desolvation forming part of the complexation process. On the other hand, proteins from human serum present a higher binding affinity to PCL NPs (as compared to HSA protein) which can also be classified as non-covalent bonding. Moreover, serum proteins have much higher binding affinity with PCL NPs $\left(K_{B}=7.52^{x} 10^{5}\right)$ than with PLGA NPs $\left(3.01^{x} 10^{3}\right)$. This is probably due to higher hydrophobicity of PCL NPs $v s$. PLGA NPs as demonstrated by the fluorescence quenching assays.

\subsection{Detection of NPs protein coronas with SDS-PAGE}

One dimensional polyacrylamide gel electrophoresis was performed to qualitatively and semi quantitatively analyze the corona fingerprint, i.e. unbound (wash 1), weakly bound corona (wash 2) and strongly bound corona (wash 3) to PLGA and PCL NPs, respectively. A small fraction of each wash was size fractionated and visualized on a $12 \%$ SDS gel (see Fig. S2 in Supplementary data). Well resolved protein bands with similar profiling patterns were observed for each wash with the exception of wash 3 . Only one distinct band was detected in wash 3 of PCL NPs whereas three bands were detected in the same wash for PLGA NPs. Protein bands were excised from the gel, trypsin digested and the resulting peptides analyzed using LC-MS/MS.

\subsection{Identification of proteins in the corona layers of PCL and PLGA NPS}

The protocol used in this study was able to identify 29 and 10 proteins in all fractions of the PCL and PLGA NPs, respectively (Table 2). Only proteins that contained at least two unique peptides with a probability score equal to or greater than $95 \%$ were accepted as positive identities [39].

Distinct differences in protein identifications were observed between PLGA NPs and PCL NPs fractions. For example, apolipoproteins (APOA, APOB, APOE) were only identified in the weakly and strongly adsorbed fractions of PCL NPs. Apolipoproteins also contain lipid binding domains which are preferentially adsorbed by hydrophobic materials $[10,40,41]$. Interestingly, the binding of apolipoprotein E, only present in the weakly bound corona of PCL NPs, is one of the main types of proteins which adsorb on liposomes and polymeric NPs [42] and not inorganic NPs [43]. Kreuter and co-workers suggested that apolipoprotein E plays a paramount role in the delivery of a number of NP-bound drugs across the blood-brain barrier (BBB) [44], brought about by the initiation of a receptor-mediated endocytosis across the $\mathrm{BBB}$, which could influence the intracellular transport of nanocarriers in vivo [45].

Other proteins that were identified in the weakly and/or strongly adsorbed fractions of PCL NPs included immunoglobulins (IGG1, IGK, IGHA, HV374, KV320 and IGLC), vitronectin (VTNC), transferrin (TRFE), complement proteins (C3 and C5), haptoglobin, antithrombinIII, alpha-I-antitrypsin, alpha-1B-glycoprotein, ceruloplasmin, heparin cofactor 2, hemopexin, cystatin-A, inter-alpha-trypsin inhibitor heavy chain $\mathrm{H} 1$, alpha-1-antichymotrypsin, plasma protease $\mathrm{C} 1$ inhibitor and Insulin-like growth factor-binding protein complex acid labile. Similar findings were reported for hydrophobic NPs and for PEG-modified PCL NPs $[46,47]$. The presence of transferrin on the weakly adsorbed layer may assist with targeting of the PCL NPs, particularly for cancer therapy [48].

\subsection{Semi-quantitative analysis of the PCL NPS and PLGA NPs corona proteins}

In an attempt to differentiate the protein/surface affinity between the two NP types, we comparatively analysed the data of each wash fraction. The relative quantification was elaborated statistically using 


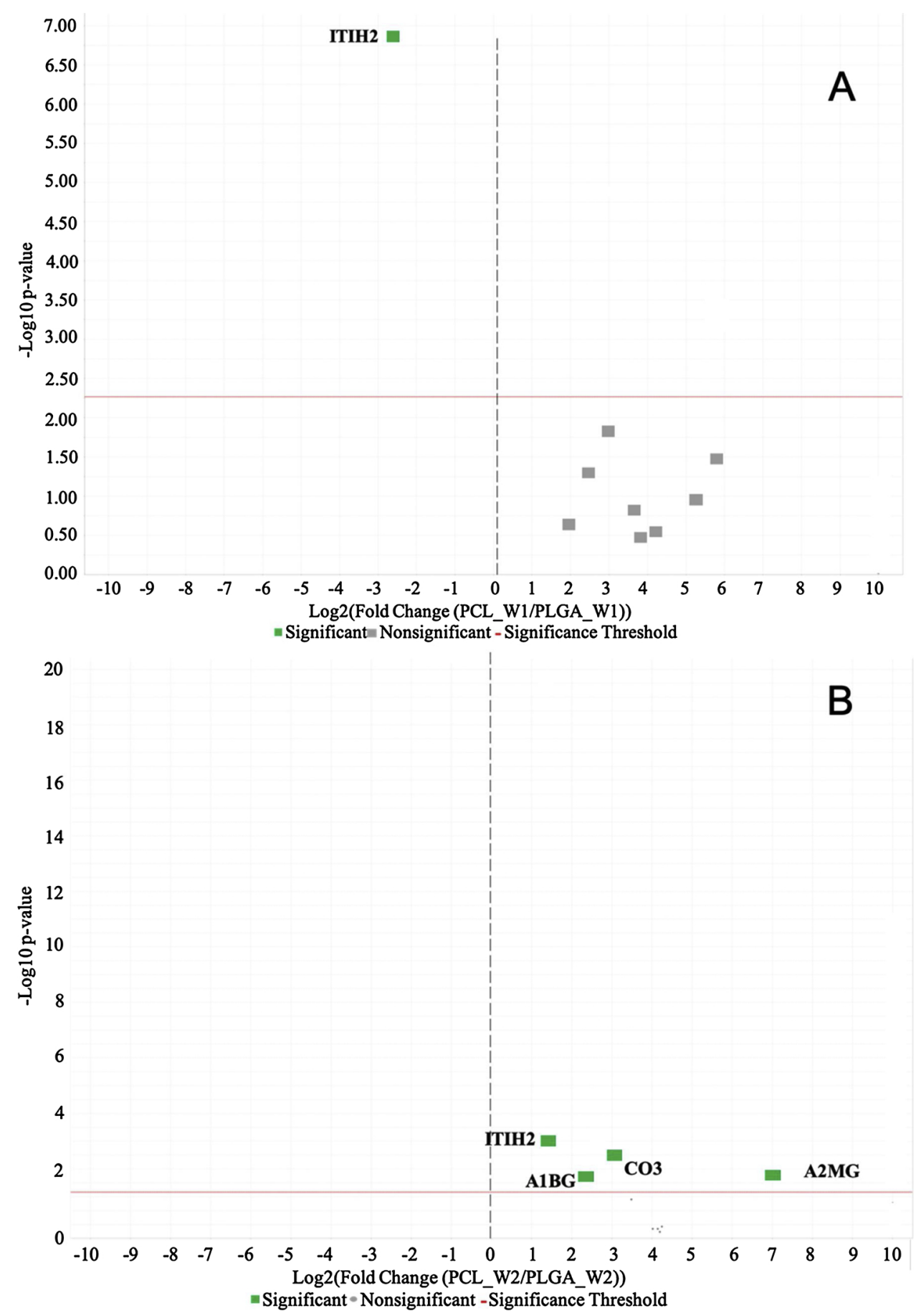

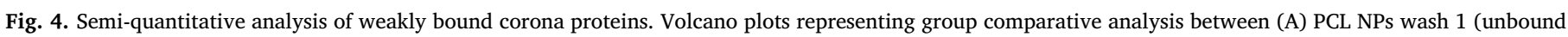
proteins) and PLGA NPs wash 1; (B) PCL NPs wash 2 (weakly bound corona) and PLGA NPs wash 2.

the Fisher's Exact Test considering the variability across the technical replicates. The results are reported as volcano plots (Fig. 4), with the binary logarithm of the fold change (i.e. the amount of a protein in the corona of a type of NPs versus the amount of the same protein in the corona of another NPs type) in the $\mathrm{x}$-axis and the $-\log 10$ of the adjusted p-value on the y-axis, accounting for statistical significance. In a one-toone comparison between PCL NPs wash 1 (unbound proteins) and PLGA NPs wash 1, most proteins identified (apart from one) appeared below the significance threshold due to low internal variability in the wash fractions of these NPs (Fig. 4A). The protein that appeared above the significant threshold was inter-alpha-trypsin inhibitor heavy chain $\mathrm{H} 2$ (ITIH2) and based on the $\log 2$ fold change value, this protein is placed between -3 and 2 . ITIH2 was identified as a protein with the highest significant correspondence between PCL NPs wash 1 and PLGA NPs wash 1.

A similar trend was observed for PCL NPs wash 2 (weakly bound corona) versus PLGA NPs wash 2 where most of the identified proteins appeared below the significance threshold line (Fig. 4B). Proteins (ITIH2, CO3, A2MG and A1BG) above the threshold line have log2 fold change values that range between +1 and +7 , which suggests that they were more likely expressed in the weakly bound corona fraction of PCL NPs compared to PLGA NPs. Furthermore, this suggests that these proteins could have a preferential affinity for this specific type of polymeric NPs, i.e. PCL NPs. In the comparison of PCL NPs wash 3 

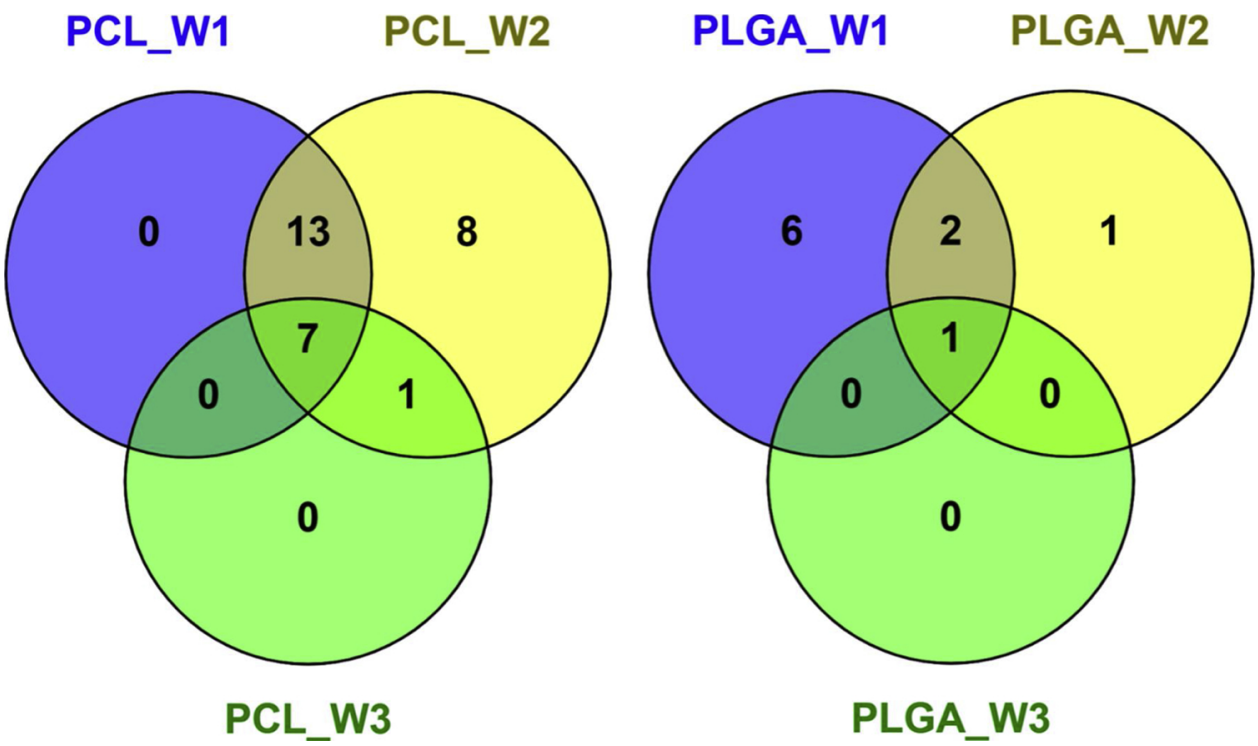

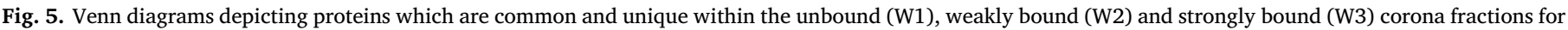
PCL NPs and PLGA NPs as identified by mass spectrometry.

(strongly bound corona) to PLGA NPs wash 3, all the positively identified proteins were detected below the significance threshold indicating that the relative amounts of these single proteins did not differ in the wash fraction of PCL NPs and PLGA NPs (plot not shown).

\subsection{Common and unique proteins adsorbed onto the PCL NPs and PLGA} NPS

The Venn diagrams in Figs. 5 and 6 illustrate the number of shared and unique proteins adsorbed onto PCL NPs and PLGA NPs. Apart from PCL wash 2 containing eight unique proteins, no unique proteins were observed in the other two wash fractions of PCL NPs (Fig. 5). However, a total of 13 proteins were shared between PCL wash 1 (unbound proteins) and PCL wash 2 (weakly bound corona) whereas one protein was shared between wash 2 and wash 3 (strongly bound corona). A total of seven proteins were common amongst the three wash fractions. For the 10 proteins identified in the wash fractions of PLGA NPs (Fig. 5), six proteins were unique to PLGA wash 1 and one to PLGA wash 2. However, no unique proteins were identified in PLGA wash 3 (hard corona) when compared to the other two wash fractions. Furthermore, we observed that two proteins were shared between PLGA wash 1 and PLGA wash 2, with one protein shared between all wash fractions of PLGA NPs.

For the comparison between the proteins identified in the unbound fraction of PCL and PLGA NPs (Fig. 6 PCL_W1 and PLGA_W1), 12 proteins were unique to PCL NPs and only one to PLGA NPs. A total of eight proteins were shared between these two NPs in the unbound fractions. Of the 29 proteins identified in the weakly bound fractions, four were shared between PCL and PLGA NPs and 25 were unique to
PCL NPs (Fig. 6 PCL_W2 and PLGA_W2). No unique proteins were identified for PLGA NPs in the weakly bound corona. A similar trend was observed in the strongly bound fraction of PCL and PLGA NPs (Fig. 6 PCL_W3 and PLGA_W3). Only one protein was shared between the NPs with seven proteins unique to PCL NPs.

\section{Conclusion}

We have reported on the interactions of PLGA and PCL NPs with serum proteins, describing thermodynamics of protein binding and semi quantitative detection of proteins in the weakly bound and strongly bound corona layers of (non-surface modified) PLGA and PCL NPs. Our results indicate that serum proteins have greater affinity (binding constants) for PCL NPs than PLGA NPs. These observations are likely attributed to the more hydrophobic nature of PCL NPs in comparison to PLGA NPs. Using LC-MS/MS, we detected 29 different proteins present in the corona of PCL NPs and 10 proteins present in the corona of PLGA NPs, representing their unique proteome fingerprints. Some proteins were unique to the PCL NPs. Our data was generated using human serum, and together with other studies conducted using human plasma, will contribute towards understanding the bio-identity of NPs and the nature of binding, which is important for rational design of NP drug delivery systems as this 'new identity' influences NPs cell targeting and uptake as well as the absorption, distribution, metabolism, elimination and toxicity profile of the NPs.

\section{CRediT authorship contribution statement}

Myolisi Ndumiso: Methodology, Investigation, Formal analysis.
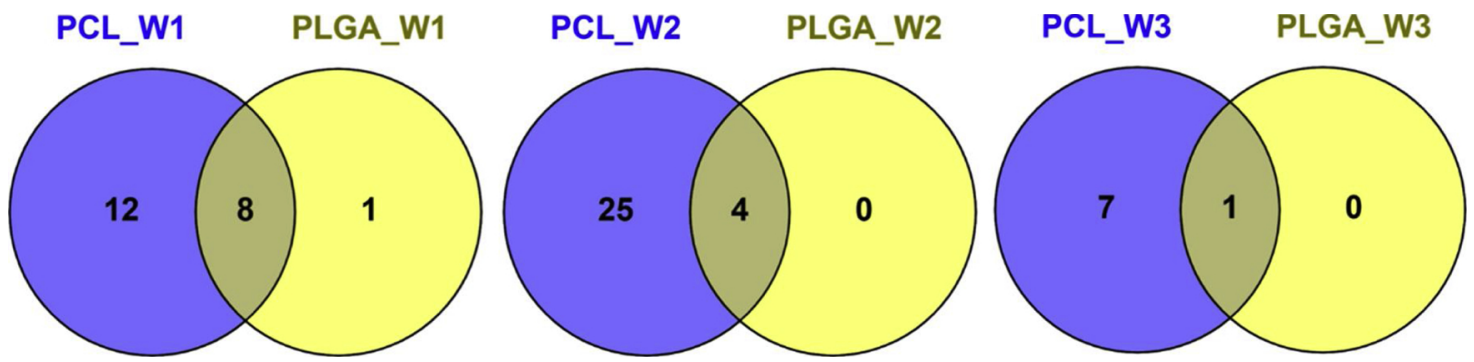

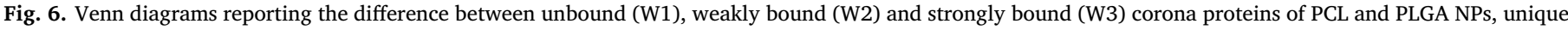
proteins and their respective overlap. 
Nela Buchtová: Methodology, Investigation, Writing - original draft, Writing - review \& editing, Formal analysis, Visualization. Lizex Husselmann: Methodology, Investigation, Formal analysis, Writing review \& editing. Gadija Mohamed: Methodology, Investigation, Formal analysis, Writing - review \& editing. Ashwil Klein: Methodology, Formal analysis, Writing - review \& editing. Marique Aucamp: Methodology, Formal analysis, Writing - review \& editing. David Canevet: Resources, Methodology, Investigation. Sarah D'Souza: Methodology, Investigation, Writing - review \& editing. Retsepile E. Maphasa: Methodology, Investigation. Frank Boury: Supervision, Resources. Admire Dube: Conceptualization, Supervision, Methodology, Writing - review \& editing, Project administration, Resources.

\section{Declaration of Competing Interest}

The authors declare that they have no known competing financial interests or personal relationships that could have appeared to influence the work reported in this paper.

\section{Acknowledgements}

AD acknowledges funding from the Fogarty International Center of the National Institutes of Health under Award Number K43TW010371. The content is solely the responsibility of the author and does not necessarily represent the official views of the National Institutes of Health. This work is based on research supported in part by the National Research Foundation of South Africa (grant number 116669) and Campus France Agency (PROTEA 2019). This research project was conducted in the framework of the regional program "NANOFAR+", supported by the French Région Pays de la Loire and the Erasmus Mundus Joint Doctorate NanoFar (funded by EACEA; grant number 2012 0028).

\section{Appendix A. Supplementary data}

Supplementary material related to this article can be found, in the online version, at doi:https://doi.org/10.1016/j.colsurfb.2020.110816.

\section{References}

[1] D. Bobo, K.J. Robinson, J. Islam, K.J. Thurecht, S.R. Corrie, Nanoparticle-based medicines: a review of FDA-approved materials and clinical trials to date, Pharm. Res. 33 (10) (2016) 2373-2387.

[2] E.S. Lee, J.M. Shin, S. Son, H. Ko, W. Um, S.H. Song, et al., Recent advances in polymeric nanomedicines for cancer immunotherapy, Adv. Healthc. Mater. 8 (4) (2019) 1801320.

[3] F. Danhier, E. Ansorena, J.M. Silva, R. Coco, A. Le Breton, V. Préat, PLGA-based nanoparticles: an overview of biomedical applications, J. Control. Release 161 (2) (2012) 505-522.

[4] K.S. Soppimath, T.M. Aminabhavi, A.R. Kulkarni, W.E. Rudzinski, Biodegradable polymeric nanoparticles as drug delivery devices, J. Control. Release 70 (1) (2001) $1-20$.

[5] D. Mondal, M. Griffith, S.S. Venkatraman, Polycaprolactone-based biomaterials for tissue engineering and drug delivery: current scenario and challenges, Int. J. Polym. Mater. Polym. Biomater. 65 (5) (2016) 255-265.

[6] H.K. Makadia, S.J. Siegel, Poly lactic-co-glycolic acid (PLGA) as biodegradable controlled drug delivery carrier, Polymers 3 (3) (2011) 1377-1397.

[7] D.A. Brill, J.A. MacKay, Image-driven pharmacokinetics: nanomedicine concentration across space and time, Nanomedicine 10 (18) (2015) 2861-2879.

[8] D. Nierenberg, A.R. Khaled, O. Flores, Formation of a protein corona influences the biological identity of nanomaterials, Rep. Pract. Oncol. Radiother. 23 (4) (2018) 300-308.

[9] J. Müller, D. Prozeller, A. Ghazaryan, M. Kokkinopoulou, V. Mailänder, S. Morsbach, et al., Beyond the protein corona - lipids matter for biological response of nanocarriers, Acta Biomater. 71 (2018) 420-431.

[10] S. Ritz, S. Schöttler, N. Kotman, G. Baier, A. Musyanovych, J. Kuharev, et al., Protein corona of nanoparticles: distinct proteins regulate the cellular uptake, Biomacromolecules 16 (4) (2015) 1311-1321.

[11] D. Maiolo, P. Del Pino, P. Metrangolo, W.J. Parak, F. Baldelli Bombelli, Nanomedicine delivery: does protein corona route to the target or off road? Nanomedicine 10 (21) (2015) 3231-3247.

[12] V. Skakauskas, P. Katauskis, Modeling of a single nanoparticle interaction with the human blood plasma proteins, J. Biol. Phys. 44 (4) (2018) 605-617.

[13] J.W. Hickey, J.L. Santos, J.-M. Williford, H.-Q. Mao, Control of polymeric nanoparticle size to improve therapeutic delivery, J. Control. Release 219 (2015) 536-547

[14] O. Vilanova, J.J. Mittag, P.M. Kelly, S. Milani, K.A. Dawson, J.O. Rädler, et al., Understanding the kinetics of protein-nanoparticle corona formation, ACS Nano 10 (12) (2016) 10842-10850.

[15] C. Fedeli, D. Segat, R. Tavano, L. Bubacco, G. De Franceschi, P. Polverino de Laureto, et al., The functional dissection of the plasma corona of $\mathrm{SiO}_{2}$-NPs spots histidine rich glycoprotein as a major player able to hamper nanoparticle capture by macrophages, Nanoscale 7 (42) (2015) 17710-17728.

[16] M. Li, K.T. Al-Jamal, K. Kostarelos, J. Reineke, Physiologically based pharmacokinetic modeling of nanoparticles, ACS Nano 4 (11) (2010) 6303-6317.

[17] E. Mahon, A. Salvati, F. Baldelli Bombelli, I. Lynch, K.A. Dawson, Designing the nanoparticle-biomolecule interface for "targeting and therapeutic delivery", J. Control. Release 161 (2) (2012) 164-174.

[18] N. Welsch, Y. Lu, J. Dzubiella, M. Ballauff, Adsorption of proteins to functional polymeric nanoparticles, Polymer 54 (12) (2013) 2835-2849.

[19] S. Milani, F. Baldelli Bombelli, A.S. Pitek, K.A. Dawson, J. Rädler, Reversible versus irreversible binding of transferrin to polystyrene nanoparticles: soft and hard corona, ACS Nano 6 (3) (2012) 2532-2541.

[20] R. Gossmann, E. Fahrländer, M. Hummel, D. Mulac, J. Brockmeyer, K. Langer, Comparative examination of adsorption of serum proteins on HSA- and PLGA-based nanoparticles using SDS-PAGE and LC-MS, Eur. J. Pharm. Biopharm. 93 (2015) 80-87.

[21] K. Sempf, T. Arrey, S. Gelperina, T. Schorge, B. Meyer, M. Karas, et al., Adsorption of plasma proteins on uncoated PLGA nanoparticles, Eur. J. Pharm. Biopharm. 85 (1) (2013) 53-60.

[22] D. Glancy, Y. Zhang, J.L.Y. Wu, B. Ouyang, S. Ohta, W.C.W. Chan, Characterizing the protein corona of sub-10 nm nanoparticles, J. Control. Release (2019).

[23] C.D. Walkey, J.B. Olsen, F. Song, R. Liu, H. Guo, D.W.H. Olsen, et al., Protein corona fingerprinting predicts the cellular interaction of gold and silver nanoparticles, ACS Nano 8 (3) (2014) 2439-2455.

[24] D. Joseph, S. Sachar, N. Kishore, S. Chandra, Mechanistic insights into the interactions of magnetic nanoparticles with bovine serum albumin in presence of surfactants, Colloids Surf. B Biointerfaces 135 (2015) 596-603.

[25] A. Dube, J.L. Reynolds, W.-C. Law, C.C. Maponga, P.N. Prasad, G.D. Morse, Multimodal nanoparticles that provide immunomodulation and intracellular drug delivery for infectious diseases, Nanomed. Nanotechnol. Biol. Med. 10 (4) (2014) 831-838.

[26] Y. Xiao, M.R. Wiesner, Characterization of surface hydrophobicity of engineered nanoparticles, J. Hazard. Mater. 215-216 (2012) 146-151.

[27] S.R. Piersma, M.O. Warmoes, M. de Wit, I. de Reus, J.C. Knol, C.R. Jiménez, Whole gel processing procedure for GeLC-MS/MS based proteomics, Proteome Sci. 11 (1) (2013) 17.

[28] E.H. Hooijberg, M. Miller, C. Cray, P. Buss, G. Steenkamp, A. Goddard, Serum protein electrophoresis in healthy and injured southern white rhinoceros (Ceratotherium simum simum), PLoS One 13 (7) (2018) e0200347.

[29] Maria GN-A, P.-S. Elizabeth, G.-R. Adriana, L.-B. David, Single emulsion-solvent evaporation technique and modifications for the preparation of pharmaceutical polymeric nanoparticles, Recent Pat. Drug Deliv. Formul. 6 (3) (2012) 209-223.

[30] P. Taylor, Ostwald ripening in emulsions, Adv. Colloid Interface Sci. 75 (2) (1998) 107-163.

[31] D. Cheng, X. Cao, H. Gao, X. Ye, W. Li, Y. Wang, Engineering PLGA doped PCL microspheres with a layered architecture and an island-sea topography, RSC Adv. 4 (18) (2014) 9031-9038.

[32] M. Mahmoudi, I. Lynch, M.R. Ejtehadi, M.P. Monopoli, F.B. Bombelli, Laurent S. protein-Nanoparticle interactions: opportunities and challenges, Chem. Rev. 111 (9) (2011) 5610-5637.

[33] P. Ghosh, J. Patwari, S. Dasgupta, Complexation with human serum albumin facilitates sustained release of morin from polylactic-co-glycolic acid nanoparticles, J. Phys. Chem. B 121 (8) (2017) 1758-1770.

[34] V. Parikh, P. Gupta, Thermodynamic analysis of r-hGH-polymer surface Interaction using isothermal titration calorimetry, Growth Horm. Igf Res. 42-43 (2018) 86-93.

[35] S. Zeng, Y.-m M. Huang, C.-e A. Chang, W. Zhong, Protein binding for detection of small changes on a nanoparticle surface, Analyst 139 (6) (2014) 1364-1371.

[36] N. Welsch, A.L. Becker, J. Dzubiella, M. Ballauff, Core-shell microgels as "smart" carriers for enzymes, Soft Matter 8 (5) (2012) 1428-1436.

[37] Y. Hoshino, K. Imamura, M. Yue, G. Inoue, Y. Miura, Reversible absorption of CO2 triggered by phase transition of amine-containing micro- and nanogel particles, $\mathrm{J}$. Am. Chem. Soc. 134 (44) (2012) 18177-18180.

[38] R. Huang, B.L.T. Lau, Biomolecule-nanoparticle interactions: elucidation of the thermodynamics by isothermal titration calorimetry, Biochim. Biophys. Acta (BBA) - Gen. Subj. 1860 (5) (2016) 945-956.

[39] Z.S. Al-Ahmady, M. Hadjidemetriou, J. Gubbins, K. Kostarelos, Formation of protein corona in vivo affects drug release from temperature-sensitive liposomes, $\mathrm{J}$. Control. Release 276 (2018) 157-167.

[40] C.D. Walkey, W.C.W. Chan, Understanding and controlling the interaction of nanomaterials with proteins in a physiological environment, Chem. Soc. Rev. 41 (7) (2012) 2780-2799.

[41] S. Meister, I. Zlatev, J. Stab, D. Docter, S. Baches, R.H. Stauber, et al., Nanoparticulate flurbiprofen reduces amyloid- $\beta 42$ generation in an in vitro blood-brain barrier model, Alzheimers Res. Ther. 5 (6) (2013) 51.

[42] J. Klein, Probing the interactions of proteins and nanoparticles, Proc. Natl. Acad. Sci. U. S. A. 104 (7) (2007) 2029-2030.

[43] M. Rahman, S. Laurent, N. Tawil, L.H. Yahia, M. Mahmoudi, Nanoparticle and 
Protein Corona. Protein-Nanoparticle Interactions: The Bio-Nano Interface, Springer, Berlin, Heidelberg, 2013, pp. 21-44 Berlin Heidelberg.

[44] J. Kreuter, D. Shamenkov, V. Petrov, P. Ramge, K. Cychutek, C. Koch-Brandt, et al., Apolipoprotein-mediated transport of nanoparticle-bound drugs across the bloodbrain barrier, J. Drug Target. 10 (4) (2002) 317-325.

[45] J. Kreuter, Mechanism of polymeric nanoparticle-based drug transport across the blood-brain barrier (BBB), J. Microencapsul. 30 (1) (2013) 49-54.

[46] T. Cedervall, I. Lynch, S. Lindman, T. Berggård, E. Thulin, H. Nilsson, et al., Understanding the nanoparticle-protein corona using methods to quantify exchange rates and affinities of proteins for nanoparticles, Proc. Natl. Acad. Sci. U. S.
A. 104 (7) (2007) 2050-2055.

[47] R. Gref, M. Lück, P. Quellec, M. Marchand, E. Dellacherie, S. Harnisch, et al., 'Stealth' corona-core nanoparticles surface modified by polyethylene glycol (PEG): influences of the corona (PEG chain length and surface density) and of the core composition on phagocytic uptake and plasma protein adsorption, Colloids Surf. B Biointerfaces 18 (3) (2000) 301-313.

[48] J.Y. Yhee, S.J. Lee, S. Lee, S. Song, H.S. Min, S.-W. Kang, et al., Tumor-targeting transferrin nanoparticles for systemic polymerized siRNA delivery in tumor-bearing mice, Bioconjug. Chem. 24 (11) (2013) 1850-1860. 